Check for updates

Cite this: RSC Adv., 2018, 8, 19272

Received 26th March 2018

Accepted 14th May 2018

DOI: $10.1039 / c 8 r a 02610 f$

rsc.li/rsc-advances

\title{
Rheological phase reaction synthesis and electrochemical performance of rufigallol anode for lithium ion batteries $\dagger$
}

\author{
Xiaoyan Han, (D)* Guanyu Lin, Qing Zhang and Yingkui Yang (D)
}

1,2,3,5,6,7-hexahydroxy-anthraquinone (rufigallol) and its metal-organic complex (rufigallol-Li/Ni, R-LN) were both synthesized. The electrochemical performance investigation of rufigallol and R-LN as anodes for lithium ion batteries indicates that pure rufigallol delivers high initial capacity but poor cycling stability, by contrast, the R-LN complex exhibits high initial capacity and excellent cycling stability.

Lithium ion batteries (LIBs) have proven to be clean and efficient energy-storage technologies to meet the growing demand for green and sustainable electric power storage. Considering the sustainability, low cost, abundant natural sources, structural design with tolerance for variable functional groups, fast reaction kinetics and high power density, organic electrode materials have been the most competitive alternative to traditional inorganic materials. ${ }^{1-6}$ Quinone organic materials with carbonyl functional group have received great concern for their high theoretical capacities and reaction reversibility. While, the dissolution of small molecule quinones in the organic electrolyte and the resulting capacity attenuation have restricted their application. Therefore, it is urgently demanded to design new organic electrode materials with high energy efficiency and good cycling stability. Among small molecule quinones, 1,2,3,5,6,7-hexahydroxy-anthraquinone (rufigallol) as a critical component has been widely used in dye industry, drug synthesis, and organic materials..$^{7-10}$ Rufigallol was firstly synthesized in $1836 .{ }^{11}$ Since then, very little efficient method for the preparation of rufigallol has been reported. Recently, Bisoyi and Kumar's research indicates that the rufigallol can be achieved by self-condensation of gallic acid in the presence of sulfuric acid under microwave-assisted, and the yield reached $86 \%{ }^{12}$ Also, as far as we know, there is no correlative literature exists about rufigallol being used as electrode materials for lithium ion batteries.

It is well-known that the dissolution of organic molecule in the electrolyte can be effectively suppressed via salt formation. Therefore, constructing the metal-organic complex is an efficient way to obtain a stable and flexible framework as well as a better cycling stability. ${ }^{13-19}$ In our previous study, ${ }^{20,21}$ we have

Key Laboratory of Catalysis and Materials Science of the State Ethnic Affairs Commission \& Ministry of Education, South-Central University for Nationalities, Wuhan 430074, Hubei Province, China.E-mail: xyhan@scuec.edu.cn

$\dagger$ Electronic supplementary information (ESI) available. See DOI: $10.1039 / \mathrm{c} 8 \mathrm{ra0} 2610 \mathrm{f}$ successfully realized the improvement of cycling stability for 3,4,9,10-perylene-tetracarboxylic acid-dianhydride (NTCDA) through the introducing of $\mathrm{Li} / \mathrm{Ni}$ or $\mathrm{Co} / \mathrm{Mn}$ to the matrix material. The obtained metal-organic complex, namely, $\mathrm{Li} / \mathrm{Ni}$ 1,4,5,8-naphthalenetetracarboxylate or $\mathrm{Co} / \mathrm{Mn}-1,4,5,8-$ naphthalenetetracarboxylate, showed a high specific capacity and a good cycling stability.

Herein, we developed a simple, economical and effective rheological phase method ${ }^{22}$ to synthesize the rufigallol with high yield and investigated its electrochemical application in lithium ion batteries. In view of the easily connecting of hydroxyl groups in aromatic carbonyl compound for rufigallol with metal ions, in order to modify the cycling stability of pure rufigallol, we synthesized rufigallol-Li/Ni complex (R-LN) through the introducing of lithium and nickel by a hydrothermal method. When used as the LIBs anode, rufigallol shows initial discharge and charge capacities of $977 \mathrm{~mA} \mathrm{~h} \mathrm{~g}{ }^{-1}$ and $460 \mathrm{~mA} \mathrm{~h} \mathrm{~g}{ }^{-1}$, respectively, which is far higher than that of traditional graphite anode. The R-LN complex delivers initial a charge capacity of $560 \mathrm{~mA} \mathrm{~h} \mathrm{~g}{ }^{-1}$ and still remain at about $500 \mathrm{~mA} \mathrm{~h} \mathrm{~g}^{-1}$ after 100 cycles, indicating a good electrochemical performance. Our work presents a new quinone-based organic materials with high capacity and competitive cycling stability, which enriches the organic electrode materials.

\section{Experiment section}

Rufigallol was synthesized from gallic acid and sulfuric acid as precursors by a simple rheological phase method. The gallic acid monohydrate was purchased from commercial sources and dehydrated before using. Proper gallic acid was added slowly in sulfuric acid at $80^{\circ} \mathrm{C}$ with stirring to form a rheological mixture. Then the mixture was transfered into a Teflon container sealed in a stainless steel reactor at $120{ }^{\circ} \mathrm{C}$ for $5 \mathrm{~h}$. The obtained product was separated simply by enough distilled water with vigorous stirring and subsequently filtered, washed and dried, 
the overall yield was $95 \%$. The reaction process is expressed as follows:

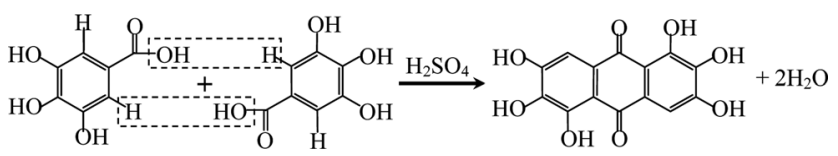

Rufigallol-Li/Ni complex (R-LN) was synthesized by a simple hydrothermal reaction by using rufigallol, $\mathrm{Ni}(\mathrm{OH})_{2}$ and $\mathrm{LiOH} \cdot \mathrm{H}_{2} \mathrm{O}$ as precursors. Rufigallol and $\mathrm{Ni}(\mathrm{OH})_{2}$ with $1: 1 \mathrm{~mol}$ ratio were mixed in ethanol solution with stirring at $70{ }^{\circ} \mathrm{C}$ for $3 \mathrm{~h}$. Then, proper $\mathrm{LiOH} \cdot \mathrm{H}_{2} \mathrm{O}$ (1: $4 \mathrm{~mol}$ ratio) was added, and further stirred for $2 \mathrm{~h}$. After that, the final R-LN product was obtained after dried at $120{ }^{\circ} \mathrm{C}$. The complex reaction process can be expressed as follows:<smiles>O=C1C(=O)c2c(cc(O)c(O)c2O)C(=O)c2c1cc(O)c(O)c2O</smiles>

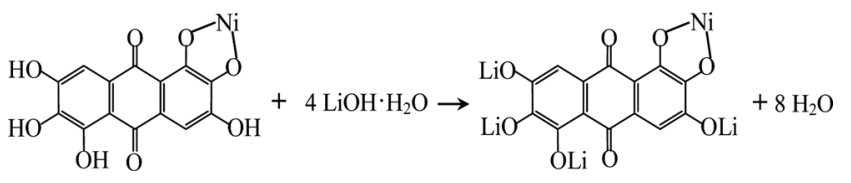

The chemical structure of the product was characterized by NMR spectroscopy $\left({ }^{1} \mathrm{H}\right.$ NMR, Bruker Avance III 400) and Fourier transform infrared spectrometer (FT-IR, Nicolet AVATAR-360). Powder X-ray diffraction (XRD) patterns were obtained by a Bruker D8-advance diffractometer (Germany) with a Ni filter and $\mathrm{Cu} \mathrm{K} \alpha$ radiation. Thermogravimetry and derivative thermogravimetry (TG/DTG) were conducted to analyze the thermal behavior of the materials in a TG thermal analyzer system (NETZSCH, TG209F3, Germany) with a nitrogen atmosphere of $20.0 \mathrm{ml} \mathrm{min}{ }^{-1}$, at a heating rate of $10{ }^{\circ} \mathrm{C} \mathrm{min}{ }^{-1}$, up to the temperature of $800{ }^{\circ} \mathrm{C}$. The samples were packed in an alumina crucible with a mass of about $6.0 \mathrm{mg}$. The surface morphology was observed by scanning electron microscope (SEM, Hitachi SU8010, Japan).

The battery performance was carried out using a 2016-type coin cells (CR2016), which consisted of a working electrode and a lithium foil as the counter electrode separated by a Celgard2300 microporous membrane. The working electrode consists of active material, acetylene black and polytetrafluoethylene (PTFE) binder with the weighting ratio of $60: 35: 5$. The active materials loading on each electrode sheet is around $3.0 \mathrm{mg}$ $\mathrm{cm}^{-2}$. A stainless-steel mesh acted as the current collector. $1 \mathrm{M}$ LipF6 solution dissolved in a $1: 1(\mathrm{v} / \mathrm{v})$ mixture of ethylene carbonate (EC) and dimethylcarbonate (DMC) was used as the electrolyte. The cells were assembled in an argon-filled glove box. The discharge/charge tests were conducted using a battery test system (Land CT2001A, China) with a scope of 0.01-3.0 V at a constant current density of $100 \mathrm{~mA} \mathrm{~g}^{-1}$. The electrochemical impedance spectroscopy (EIS) was performed on an electrochemical working station (CHI660E) using model cells. The frequency range applied in this experiment was $0.01-10^{5} \mathrm{~Hz}$ and voltage amplitude was $5 \mathrm{mV}$.

\section{Results and discussion}

Fig. 1 shows the ${ }^{1} \mathrm{H}$ NMR (400 MHz, DMSO-d6) of the synthesized rufigallol and R-LN. As can be seen from Fig. 1a, the relevant analysis data of the synthesized rufigallol are given below. $\delta$ : 7.24 (s, 2H, C-H), 9.92 (s, 2H, 2,6-OH), 10.73 (s, 2H, 3,7$\mathrm{OH}), 12.93(\mathrm{~s}, 2 \mathrm{H}, 1,5-\mathrm{OH})$. The results indicate that the $1,2,3,5,6,7$-hexahydroxy-anthraquinone (rufigallol) is successfully synthesized by the rheological phase method. In Fig. 1b, for R-LN, the peaks of hydroxyl hydrogen $(1,2,3,5,6,7-\mathrm{OH})$ sharply decrease or even disappear, and the peaks of aromatic hydrogen at C-2 and C-8 (anthraquinone ring) obviously weaken, which indicate the lose of hydrogen and the introduction of the metal ions.

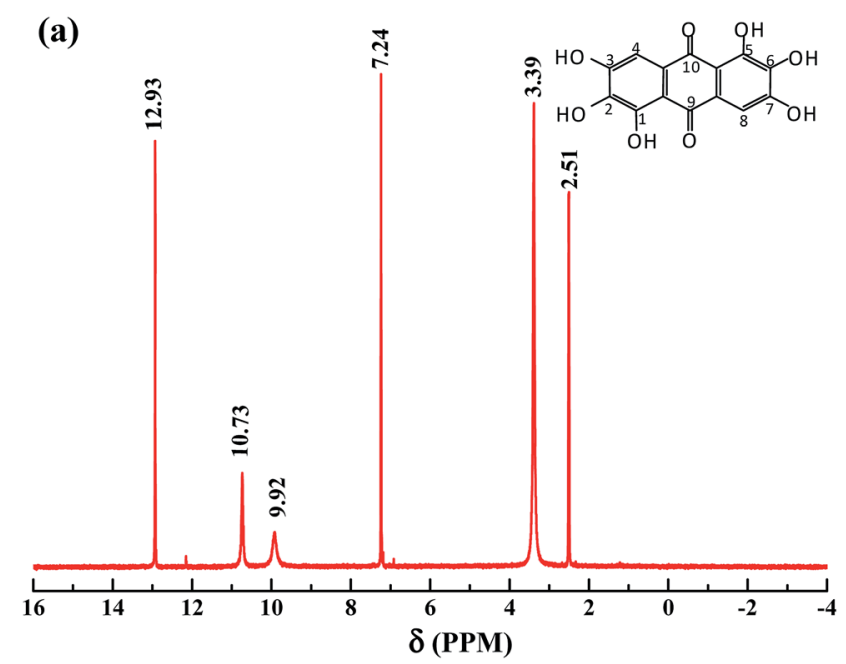

(b)

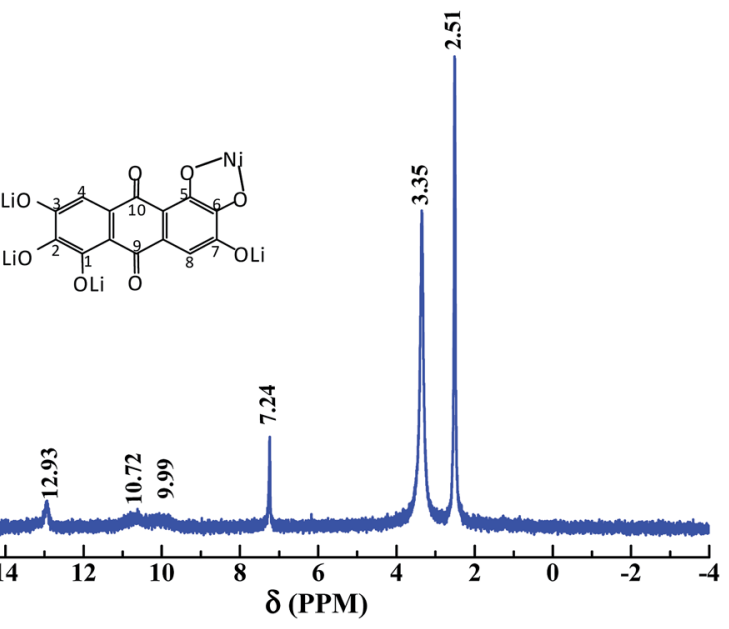

Fig. $1{ }^{1} \mathrm{H}$ NMR for the synthesized rufigallol (a) and R-LN (b). 


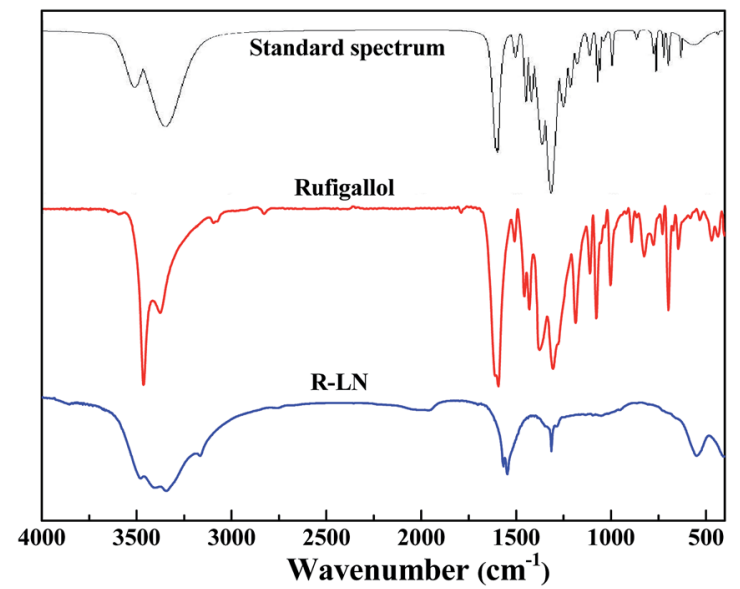

Fig. 2 Infrared spectra of rufigallol and R-LN. The standard IR absorption spectrum of rufigallol is obtained from Wiley Subscription Services, Inc. (US).

Fig. 2 presents the FT-IR spectra of the synthesized rufigallol and R-LN. The synthesized rufigallol can be best characterized by FTIR spectra, which is well consistent with the standard spectrum. Rufigallol shows distinct peaks near $1305 \mathrm{~cm}^{-1}$ and $1595 \mathrm{~cm}^{-1}$. The obvious decrease and red shift of these two peaks in $\mathrm{R}-\mathrm{LN}$ complex is caused by the interaction of $\mathrm{C}-\mathrm{O}$ with $\mathrm{Li}$ or $\mathrm{Ni}$ atom, suggesting that the $\mathrm{Li}$ or $\mathrm{Ni}$ atom exists near the $\mathrm{C}-\mathrm{O}$ of rufigallol and thus affects the molecular vibration. The $\mathrm{O}-\mathrm{H}$ stretching and bending modes of R-LN (around $3400 \mathrm{~cm}^{-1}$ and $700 \mathrm{~cm}^{-1}$ ) sharply decrease indicates that the $\mathrm{Li}$ or $\mathrm{Ni}$ atom substitutes the $\mathrm{H}$ in $\mathrm{O}-\mathrm{H}$ band to form $\mathrm{O}-\mathrm{Li}$ band (or $\mathrm{O}-\mathrm{Ni}$ band).

Fig. 3 shows the XRD patterns of the synthesized rufigallol and R-LN. All diffraction peaks of rufigallol are very sharp, which indicates a good crystallinity. The characteristic diffraction peaks are well indexed to the triclinic crystal system and $P \overline{1}$ (no. 2) space group, indicating a pure rufigallol phase of the product. However, R-LN shows poor diffraction peaks which are different from those of rufigallol. No peaks for element $\mathrm{Li}$ or Ni can be observed, which indicates that the $\mathrm{Li}$ or $\mathrm{Ni}$ atom should interconnect with rufigallol molecule in R-LN complex. The XRD results accord well with those from H NMR and FT-IR.

Fig. 4 presents the TG-DTG curves of rufigallol and R-LN. The specific temperature and weigh losses are labeled on TG-DTG curves. Generally, the little weight loss below $200{ }^{\circ} \mathrm{C}$ is probably due to volatilization of adsorbed water. The comparison of the TG data for the synthesized rufigallol and R-LN reveals that the materials show different thermal behaviors. As shown in Fig. 4a, the thermal decomposition of rufigallol proceeds in two steps: dehydration and decomposition of the rufigallol organics. The decomposition of rufigallol occurs from $300{ }^{\circ} \mathrm{C}$ to $670{ }^{\circ} \mathrm{C}$ with a weight loss of about $93 \%$, and above $670^{\circ} \mathrm{C}$ the decomposition reaction is complete. R-LN presents three distinct peaks on the DTG curve at $395^{\circ} \mathrm{C}, 595^{\circ} \mathrm{C}$ and $650^{\circ} \mathrm{C}$, respectively (see Fig. 4 b). It can be seen that the thermal decomposition of R-LN proceeds in three main steps. The weight loss occurs from $180^{\circ} \mathrm{C}$ to $410^{\circ} \mathrm{C}$ $(31.5 \%)$ can be attributed to the decomposition of the organic composition in R-LN. When the temperature increases to $800{ }^{\circ} \mathrm{C}$,

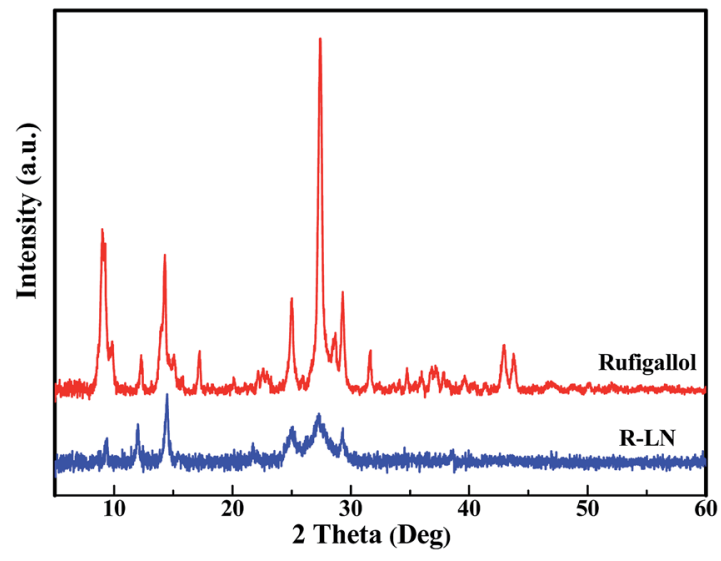

Fig. 3 XRD patterns of rufigallol and R-LN.

the weight loss is about $30.5 \%$, which can be ascribed to the formation of lithium and nickel oxides.

Fig. 5 shows the morphology of rufigallol and R-LN. Typical SEM image shows that the rufigallol is spindle-shaped bulk with a length of 30-50 $\mu \mathrm{m}$ (Fig. 5a), while its higher magnification SEM image indicates that the spindle-shaped rufigallol is composed of dendritic agglomerates (Fig. 5b). As shown in Fig. $5 c$ and d, the R-LN complex exhibits a porous structure, which consists of dispersed nano-particles with a diameter of about $50 \mathrm{~nm}$. This nano-porous structure material is expected to exhibit good electrochemical behavior for lithium ion batteries.
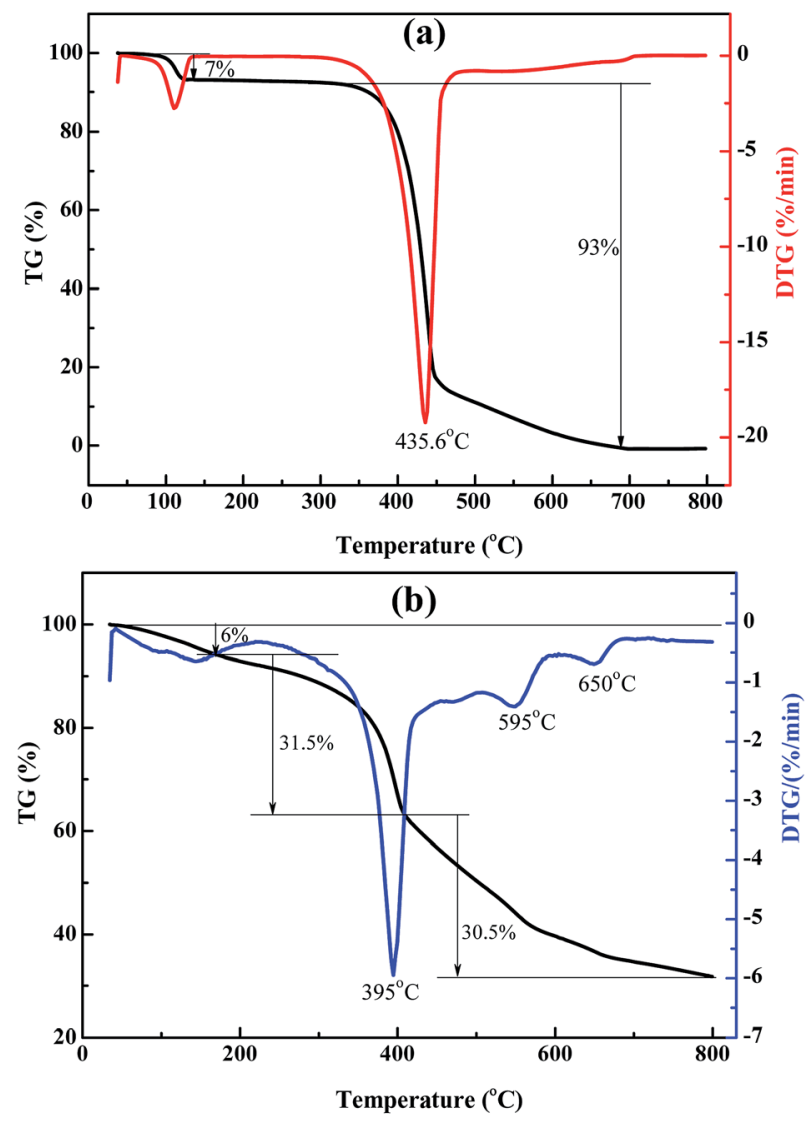

Fig. 4 TG-DTG curves of rufigallol (a) and R-LN (b). 

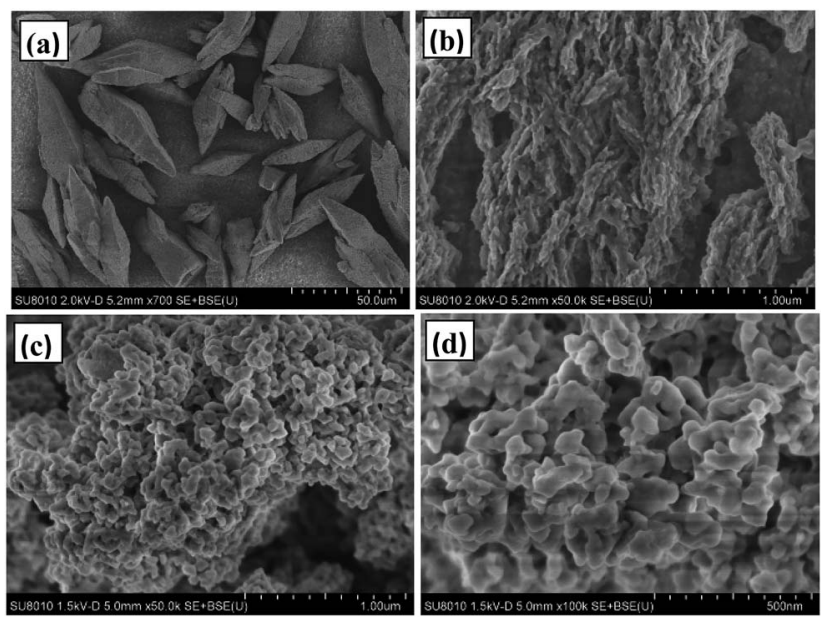

Fig. 5 SEM images of rufigallol ( $a$ and $b$ ) and R-LN (c and d)

The synthesized rufigallol and R-LN are tested as anode materials for lithium ion batteries by using galvanostatic discharge/charge cycling. Fig. 6a-e shows the electrochemical performance of rufigallol and R-LN electrode at different current densities between $0.01 \mathrm{~V}$ and 3.0 V. In Fig. 6a and b, rufigallol and R-LN show similar typical discharge/charge curves, indicating similar electrochemical behaviors. Fig. 6c compares the cycling performance of rufigallol and R-LN at $100 \mathrm{~mA} \mathrm{~g}^{-1}$. There is a little capacity reduction in the first few cycles of both rufigallol and R-LN, while the discharge and charge capacities increase gradually in the following cycles.
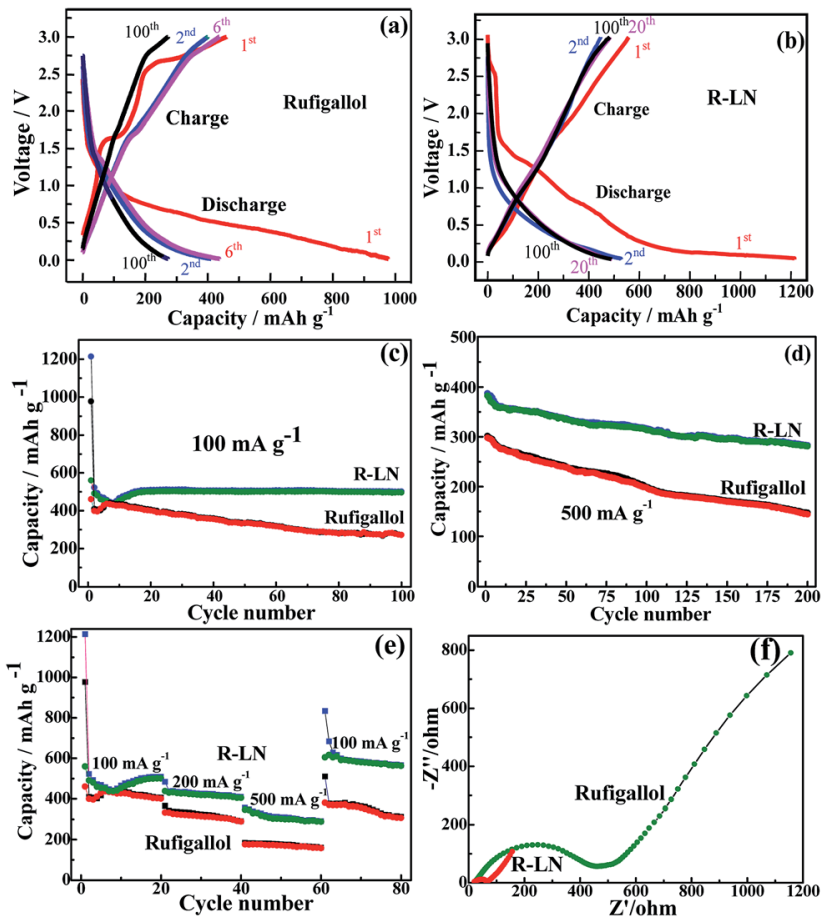

Fig. 6 Electrochemical characterization: (a) and (b) discharge/charge profiles of rufigallol and R-LN at $100 \mathrm{~mA} \mathrm{~g}^{-1}$; (c) and (d) cycling performance at different current densities; (e) rate capability; (f) EIS of rufigallol and R-LN.
Rufigallol shows initial discharge and charge capacities of $977 \mathrm{~mA} \mathrm{~h} \mathrm{~g}^{-1}$ and $460 \mathrm{~mA} \mathrm{~h} \mathrm{~g}^{-1}$, respectively. However, the charge capacity rapidly decreases to $270 \mathrm{~mA} \mathrm{~h} \mathrm{~g}^{-1}$ in 100 cycles, suggesting a poor cycling stability. In comparison, the R-LN complex shows a better cycling property. It delivers a initial charge capacity of $560 \mathrm{~mA} \mathrm{~h} \mathrm{~g}{ }^{-1}$, and still remains about $500 \mathrm{~mA} \mathrm{~h} \mathrm{~g}^{-1}$ after 100 cycles, indicating a better cycling stability. Even at a high current density of $500 \mathrm{~mA} \mathrm{~g}^{-1}$, the R-LN electrode also exhibits high reversible capacity than pure rufigallol, a high charge capacity of $281 \mathrm{~mA} \mathrm{~h} \mathrm{~g}{ }^{-1}$ can be still maintained after 200 cycles (Fig. 6d), which should be ascribed to the reduced dissolution of small organic molecular materials and enhanced metal-organic stable structure.

In addition to its improved high capacity, the R-LN complex also exhibits significant improvement in the rate capability. In Fig. 6e, the rate capability of the synthesized rufigallol and R-LN is studied. R-LN achieved the higher capacity under the same current density, showing the better rate performance than pure rufigallol. After 20 cycles, the related charge capacities of R-LN at current densities of 100,200 and $500 \mathrm{~mA} \mathrm{~g}^{-1}$ are settled on about 500, 404 and $288 \mathrm{~mA} \mathrm{~h} \mathrm{~g}^{-1}$, respectively. A reversible initial charge capacity of $604 \mathrm{~mA} \mathrm{~h} \mathrm{~g}^{-1}$ is recovered as the current density returns to $100 \mathrm{~mA} \mathrm{~g}^{-1}$ and a reversible charge capacity of $563 \mathrm{~mA} \mathrm{~h} \mathrm{~g}^{-1}$ can be recovered after 20 additional cycles, demonstrating a good reversibility of R-LN. Nevertheless, with increasing current density to $500 \mathrm{~mA} \mathrm{~g}^{-1}$, the rufigallol anode deliver poor initial capacity $\left(177 \mathrm{~mA} \mathrm{~h} \mathrm{~g}^{-1}\right)$, and after 80 cycles at different current densities, only $66 \%$ of the initial capacity is recovered as the current density returns to $100 \mathrm{~mA} \mathrm{~g}^{-1}$. The good rate performance of R-LN anode is apparently resulted from its greatly reduced electrochemical impedance. As shown in Fig. 6f, the electrochemical impedance of R-LN anode is smaller than that of pure rufigallol anode. The greatly reduced impedance of the R-LN anode is obviously due to its metal-organic stable structure, which can effectively improve the ionic conductivity. Moreover, the R-LN complex with nano-porous structure can provide abundant reaction areas and ionic transport channels. Meanwhile, compared with other metal-organic electrode materials recently reported (Table $\mathrm{S} 1 \dagger$ ), the R-LN complex displayed much better cycling stability and rate capability.

Morphologies of the fresh electrode and the retrieved electrode after electrochemical cycles of rufigallol and R-LN were observed through SEM. Fig. S1† shows that the R-LN complex can maintain its nano-porous structure before and after electrochemical cycles (Fig. S1c and $\mathrm{d} \dagger$ ). From this viewpoint, the stable electrode structural of R-LN should greatly contribute to the excellent cycling performance of the electrode. The fresh rufigallol electrode consists dispersed particles (Fig. S1a $\dagger$ ), but these particles aggregate after electrochemical cycles (Fig. S1b†), which may be the main reason for their rapid capacity fading and poor rate performance. To study the structural changes of electrodes, the XRD patterns of the fresh electrode and the retrieved electrode after electrochemical cycles were depicted in Fig. S2. $\dagger$ After the electrochemical cycles, no new diffraction peak appears, and the existing peaks do not change or shift, reflecting the very stable crystallographic 


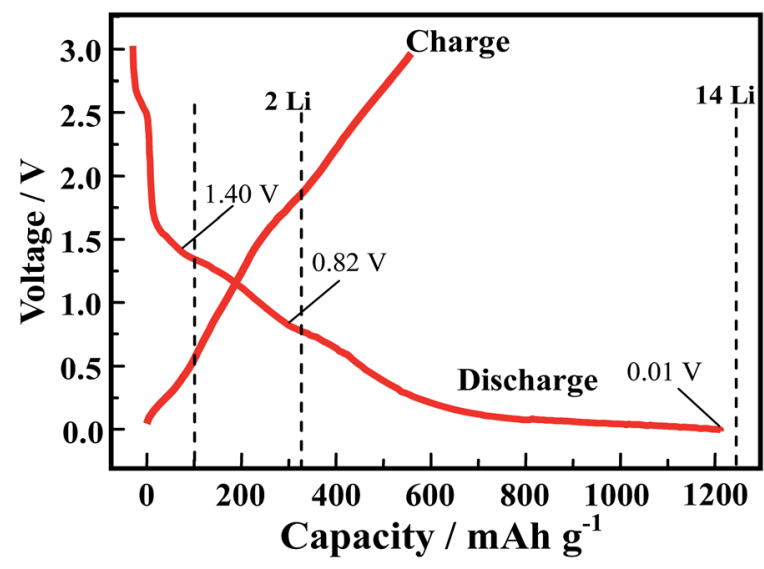

Fig. 7 Initial discharge/charge curves of R-LN at $100 \mathrm{~mA} \mathrm{~g}^{-1}$.

structure of R-LN during electrochemical processes (Fig. S2a†). However, in Fig. S2b, $\uparrow$ for the fresh rufigallol electrode, the distinct peaks at $9.15^{\circ}$ and $27.6^{\circ}$ disappeared in the retrieved electrode, suggesting the structural change of rufigallol after electrochemical cycles.

In order to explore the lithium storage mechanism, the first discharge/charge curves of R-LN is investigated as shown in Fig. 7. The first discharge curve of R-LN possesses four plateaus. The two small plateaus above $1.4 \mathrm{~V}$ lead to the irreversible capacity loss (about $100 \mathrm{~mA} \mathrm{~h} \mathrm{~g}^{-1}$ ), which disappears in the following cycles and result in a capacity reduction. Considering that for one molecule of R-LN, one Li ion insertion contributes a theoretical capacity of $69.7 \mathrm{~mA} \mathrm{~h} \mathrm{~g}{ }^{-1}$, and the discharge capacity of R-LN is $1214 \mathrm{~mA} \mathrm{~h} \mathrm{~g}{ }^{-1}$, the above data show that each R-LN molecule is capable of accepting $16 \mathrm{Li}$ ions. According to our previous research work, ${ }^{6}$ the actual Li insertion reaction in R-LN includes two major steps: the initial two Li ions inserted at a potential of above $0.82 \mathrm{~V}$ can be attributed to a lithium enolization reaction at the two carbonyl oxygens of R$\mathrm{LN}$, and then the electrochemical lithium addition reaction to the 14 unsaturated carbons occurs at below $0.82 \mathrm{~V}$. The $\mathrm{Li}$ insertion reaction of R-LN can be expressed as follows:
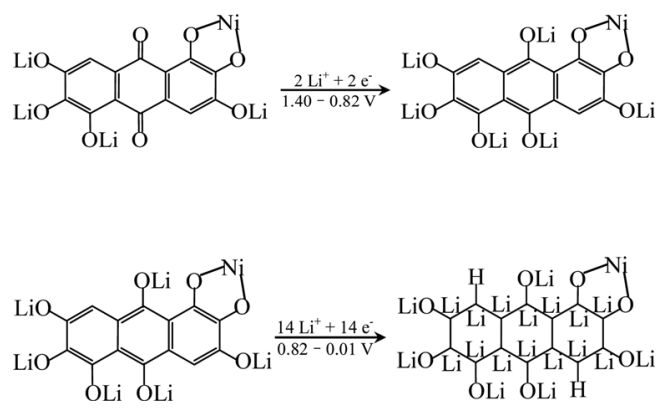

\section{Conclusions}

In this work, rufigallol has been successfully synthesized by the rheological phase method. Its metal-organic complex, namely, rufigallol-Li/Ni (R-LN), was also synthesized by hydrothermal method. The rufigallol and R-LN were both characterized as anodes for lithium ion batteries. The electrochemical investigation shows that, as anode material for lithium ion batteries, pure rufigallol shows high initial capacity but poor cycling stability, while the R-LN complex based on rufigallol exhibits high initial capacity and excellent cycling stability. Such optimized electrochemical properties of R-LN complex can be attributed to the metal-organic framework structure, which enhances the structure stability and promotes the cycling stability of small organic molecular materials. The stable framework can slow down the volume collapse and mitigate dissolution in electrolyte. Moreover, the R-LN complex with nano-porous structure, which may be contribute to the insertion/extraction of Li ions. Importantly, the strategy in this work can be extended to fabricate other quinone materials towards high lithium storage performance. Ultimately, the conveniently-synthesized rufigallol with high yield and the observation of improved electrochemical performance by introducing of metal demonstrates that quinone-based materials with stable metal-organic structure is a prospective class of organic electrode materials for lithium ion batteries. Thus, with sufficient effort and improved experimental technique these materials may possess broader practical application prospects than other organic electrode materials.

\section{Conflicts of interest}

There are no conflicts to declare.

\section{Acknowledgements}

This work was supported by the National Natural Science Foundation of China (Grant No. 21503282 and 51673061).

\section{Notes and references}

1 M. Armand, S. Grugeon, H. Vezin, S. Laruelle, P. Ribière, P. Poizot and J.-M. Tarascon, Nat. Mater., 2009, 8, 120.

2 Y. Liang, Z. Tao and J. Chen, Adv. Energy Mater., 2012, 2, 742.

3 Z. Song and H. Zhou, Energy Environ. Sci., 2013, 6, 2280.

4 J. Wang, X. M. Wang, H. F. Li, X. W. Yang and Y. G. Zhang, J. Electroanal. Chem., 2016, 773, 22.

5 B. Häupler, A. Wild and U. S. Schubert, Adv. Energy Mater., 2015, 5, 1402034.

6 X. Y. Han, G. Y. Qing, J. T. Sun and T. L. Sun, Angew. Chem., Int. Ed., 2012, 51, 5147.

7 E. S. B. Ferriara, A. N. Hulme, H. McNab and A. Quye, Chem. Soc. Rev., 2004, 33, 329.

8 E. A. Hillard, F. C. De Abreu, D. C. M. Ferreira, G. Jaouen, M. O. F. Goulart and C. Amatore, Chem. Commun., 2008, 23, 2612.

9 S. Setia, A. Soni, M. Gupta, S. Sidiq and S. K. Pal, Liq. Cryst., 2013, 40, 1364.

10 J. A. Paquette, R. E. Yardley, J. W. Y. Yu, S. H. Eichhorn and K. Maly, New J. Chem., 2016, 40, 5985.

11 V. Robiquet and U. die Gallussäure, Liebigs Ann., 1836, 19, 204.

12 H. K. Bisoyi and S. Kumar, Tetrahedron Lett., 2007, 48, 4399. 
13 J. J. Ma, H. J. Wang, X. R. Liu, L. D. Lu, L. Y. Nie, X. Yang, Y. Q. Chai and R. Yuan, Chem. Eng. J., 2017, 309, 545.

14 J. Xue, C. Fan, Q. J. Deng, M. J. Zhao, L. P. Wang, A. J. Zhou and J. Z. Li, Electrochim. Acta, 2016, 219, 418.

15 L. Q. Mu, Y. X. Lu, X. Y. Wu, Y. J. Ding, Y. S. Hu, H. Li, L. Q. Chen and X. J. Huang, Green Energy \& Environment, 2018, 3, 63.

16 Y. Wang, Q. T. Qu, G. Liu, V. S. Battaglia and H. H. Zheng, Nano Energy, 2017, 39, 200.

17 L. S. Shen, H. W. Song and C. X. Wang, Electrochim. Acta, 2017, 235, 595.
18 L. P. Wang, J. Zou, S. L. Chen, J. Y. Yang, F. Z. Qing, P. Gao and J. Z. Li, Electrochim. Acta, 2017, 235, 304.

19 L. P. Wang, C. X. Mou, B. Wu, J. Xue and J. Z. Li, Electrochim. Acta, 2016, 196, 118.

20 X. Y. Han, H. K. Mao and H. W. Liu, J. Electroanal. Chem., 2017, 802, 89.

21 X. Y. Han, F. Yi, T. L. Sun and J. T. Sun, Electrochem. Commun., 2012, 25, 136.

22 J. T. Sun, W. Xie, L. J. Yuan, K. L. Zhang and Q. Y. Wang, J. Mater. Sci. Eng. B, 1999, 64, 157. 